\section{Jejunal Myoepithelial Hamartoma Associated with Gardner's Syndrome: A Case Report}

A 23-year-old Japanese woman attended our hospital since her two brothers had been diagnosed as Gardner's syndrome sufferers. The patient had numerous epidermal cysts and osteomas. Gastrointestinal examination demonstrated gastric fundic gland polyps, a jejunal submucosal tumor, and numerous adenomatous lesions in the gastric antrum, duodenum, papilla of Vater, and colorectum. Two years later, the patient underwent a prophylactic total colectomy. On an intraoperative enteroscopy, the submucosal tumor was identified in the jejunum $70 \mathrm{~cm}$ distal to the ligament of Treitz (Figure 1): the lesion was subsequently locally resected. Histologically, the tumor was composed of whorls of excessive smooth muscle surrounding mucous glands and small cysts lined by flattened epithelia, containing neither pancreatic nor malignant tissue (Figure 2). Tiny jejunal adenomas and lymphoid polyps in the terminal ileum were also confirmed by endoscopic biopsy. In the resected colon, approximately 400 adenomas were identified.

Patients with Gardner's syndrome have been recognized as developing various abnormalities of endodermal, mesodermal, and ectodermal origin. However, a gastrointestinal mesenchymal tumor has never been reported, apart from lymphoid polyps in the ileum (1).

Myocpithelial hamartoma, originally described by Clarke (2), is an unusual submucosal tumor. Most investigators regard it as a form of pancreatic heterotopia rather than a true hamartomata (3). We feel that the term "ectopic pancreas" or "pancreatic residue" is more appropriate when there is pancreatic tissue, whereas myoepithelial hamartoma with undifferentiated duct-like structures should be termed "adenomyoma", according to Clarke (2).

Since Chapple et al. (3) reviewed 37 reports, 11 additional cases of "adenomyoma" have been reported (4). This rare condition has not been previously described in a Gardner's syndrome patient, but it may have been dismissed in earlier cases because of its lack of clinical significance. In view of the predisposition of patients with Gardner's syndrome to develop various hamartomatous disorders, the jejunal myoepithelial hamartoma identified in this patient may represent one type of phenotypic expression.

K. Hizawa', M. lida , K. Aoyagi', R. Mibu', T. Yao',

M. Fujishima '

Second Dept. of Internal Medicine, Kyushu University, Fukuoka, Japan

2First Dept. of Surgery, Kyushu University, Fukuoka, Japan

${ }^{3}$ Second Dept. of Pathology, Kyushu University, Fukuoka, Japan

${ }^{+}$Division of Gastroenterology, Dept, of Medicine, Kawasaki

Medical School, Kurashiki, Japan

\section{References}

1. Iida M. Itoh H, Matsui T, et al. Ileal adenomas in postcolectomy patients with familial adenomatosis coli/Gardner's syndrome: incidence and endoscopic appearance. Dis Colon Rectum 1989; 32: 1034-8.

2. Clarke BE. Myoepithelial hamartoma of the gastrointestinal tract: a report of eight cases with comment concerning genesis and nomenclature. Arch Pathol 1940; 30: 143-52.

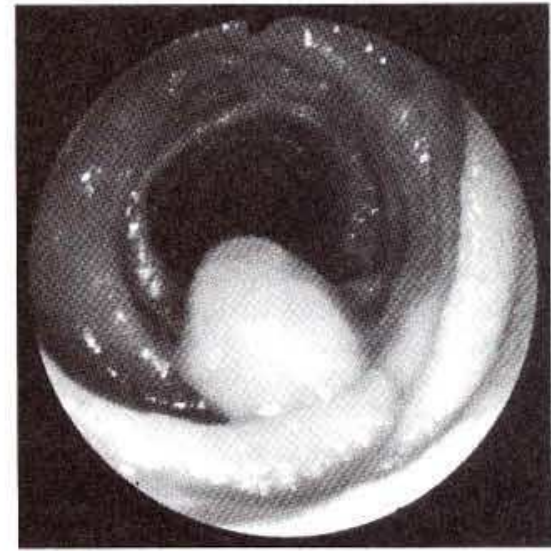

Figure 1: intraoperative enteros. copy, demonstrating a submucosal tumor in the jejunum

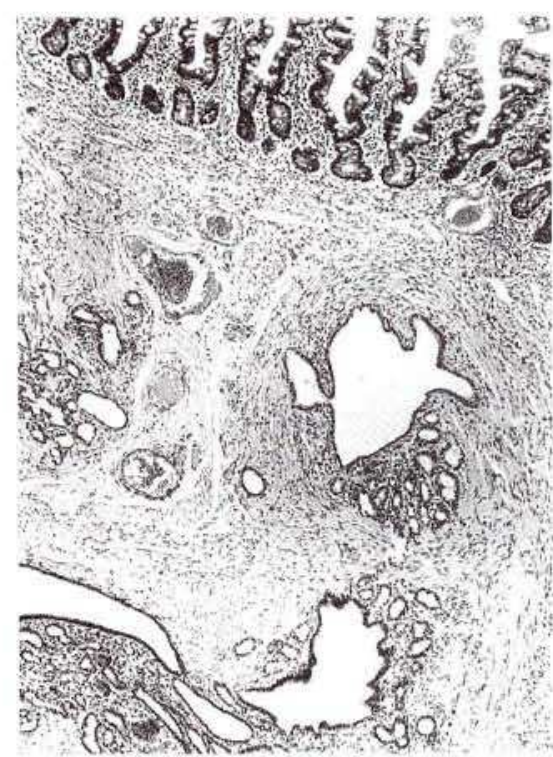

Figure 2: The histologic features are consistent with an adenomyoma (hematoxylin$\operatorname{eosin} \times 82$ ).

3. Chapple CR, Muller S, Newman J. Gastric adenocarcinoma associated with adenomyoma of the stomach. Postgrad Med J 1988: $64: 801-3$

4. Chan YF, Roche D. Adenomyoma of the small intestine in children. J Pediatr Surg 1994; 29: 1611-2,

Corresponding Author

K. Hizawa, M.D.

Second Dept. of Internal Medicine

Faculty of Medicine

Kyushu University

Maidashi 3-1-1

Fukuoka 812

Japan

Fax: +8|-92-632-2551 